\title{
Engineering environmental enterprises \\ solution, increasing the safety of water industry
}

Yuri Yuriev ${ }^{1 *}$, Konstantin Katerinin ${ }^{1}$, Oleg Konovalov ${ }^{1}$, Dmitry Shchitov ${ }^{2}$, and Pavel Sidyakin $^{2}$

${ }^{1}$ Volgograd State Technical University (VolgSTU), 400074, Volgograd, Russia

2 "North Caucasus Federal University" Institute of Service, Tourism and Design (branch) NCFU in Pyatigorsk, 355009, Stavropol, Russia

\begin{abstract}
Drainage systems are one of the most important types of engineering equipment providing the necessary sanitary and hygienic conditions for the population life and the safe operation of industrial enterprises. A necessary condition for the long-term and reliable operation of water intake facilities (hereinafter WIF) is their effective protection against corrosion caused by various factors. Search for new engineering solutions to solve the problem of corrosion and biofouling on WIF is relevant at the moment, as it gives an opportunity to provide effective protection of WIF metal surfaces, which is directly related to the increase in the environmental performance of water enterprises.
\end{abstract}

\section{Introduction}

The presented article shows the results of bench tests to assess the protection effectiveness of the gratings material at water intake facilities (hereinafter WIF) from biofouling in order to develop engineering solutions to improve the environmental safety of the designated enterprises.

The steel plates from the river water of the Volga River in the city of Volzhsky (bacterial film was present, zebra mussel and other organisms-growers, with the exception of bacteria, were absent), were compared to the plates on which the zebra mussel was present, was subject to a high degree of corrosion in the river water, with a settlement in the river water within 5 weeks. There was a gelatinous coating on the steel plates, under which ulcerations were found, up to through holes. Moreover, similar phenomena were observed precisely in the places of zebra mussel attachment. Zebra mussel was mostly alive. This makes it possible to assume that the mollusk can release into the environment various substances that improve the living conditions of the microbiocenosis located on the plate. It can also be assumed that the zebra mussel itself can release the substances (acids, enzymes and others) that are capable of either causing biocorrosion of the surfaces of materials themselves, or serve as catalysts of this process into the environment $[1,2]$.

\footnotetext{
${ }^{*}$ Corresponding author: viv_vgasu@mail.ru
} 


\section{Main part}

A similar picture could be observed with brass plates. A similar experiment was carried out - one brass plate was placed in the river water without organisms-growers, the other was settled by zebra mussel. Corrosion in the presence of mollusks was much more pronounced than just in water, despite the fact that a microbial film was present in both cases, and the composition of microorganisms was identical.

Corrosion was observed on steel plates with 3 microbial film was present on both samples without Zebra mussel, and on the samples with zebra mussel rust patches were observed; rust area was more extensive with deep pits and cavities' formation [3].

After the experiment, the bacterial film and traces of corrosion were neatly removed (rust on steel, grayish-yellow coating on brass, gelatinous mass on aluminum plates). The corrosion rate was determined by the gravimetric method. The corrosion rate is expressed in it by the mass index $\mathrm{Km}(\mathrm{g} / \mathrm{m} 2 \cdot \mathrm{h})$ according to the formula:

$$
K_{m}=\frac{m_{1}-m_{2}}{S \times t},
$$

where $\mathrm{m} 1$ and $\mathrm{m} 2$ are calculated according to the formula, $\mathrm{g}, \mathrm{S}$ determines the sample surface area, $\mathrm{m} 2$, $\mathrm{t}$ is the sample exposure time, hour.

Analysis of corrosion changes in the samples (microscopy and visual examination of corrosion products) indicates the presence of thionic and nitrifying bacteria, iron bacteria, and nitrogen fixing agents in the bacterial film.

In the case of biocorrosion and biofouling by the Zebra mussel, it is possible to speak of a symbiotic cohabitation of a number of groups of bacteria and mollusks. Presumably, mutually beneficial cohabitation of organisms is as follows. Microorganisms, causing biocorrosion and changing the coating or material surface (it becomes rougher, with numerous damages, grooves, etc.) prepare an environment for mechanical fixation of the mollusk in these irregularities using a byssus thread. The mollusk, in turn, releasing waste products, creates a food base and an environment for the development of other groups of bacteria, and the biocorrosion process continues further [4].

The data on the biocorrosion rate studies in the aquatic environment are presented in Table 1.

Table 1. Rate of biocorrosion

\begin{tabular}{|c|c|c|c|c|c|c|c|}
\hline \multirow[t]{2}{*}{ Sample } & \multirow{2}{*}{$\begin{array}{c}\mathrm{S} \\
\text { image, } \\
\mathrm{m} 2\end{array}$} & \multicolumn{2}{|c|}{ Sample mass } & \multirow{2}{*}{$\begin{array}{c}\text { Exposure } \\
\text { time t, } \\
\text { hour }\end{array}$} & \multicolumn{2}{|c|}{$\begin{array}{c}\text { Loss of } \\
\text { mass }\end{array}$} & \multirow{2}{*}{$\begin{array}{c}\text { Speed } \\
\text { corros } \\
\text { ion } \\
\mathrm{Km}, \\
\mathrm{g} / \mathrm{m}^{2} . \\
\mathrm{h}\end{array}$} \\
\hline & & $\begin{array}{c}\text { Before } \\
\text { experiment } \\
\mathrm{m}_{1}, \mathrm{~g}\end{array}$ & $\begin{array}{c}\text { after } \\
\text { experiment } \\
\mathrm{m}_{2}, \mathrm{~g}\end{array}$ & & $\begin{array}{c}\Delta \mathrm{m}, \\
\mathrm{g}\end{array}$ & $\underset{\%}{\Delta \mathrm{m}}$ & \\
\hline 1 & 0.01 & 234.2 & 210.1 & 840 & 24.1 & 10.3 & 2.87 \\
\hline 2 & 0.01 & 234.8 & 195.1 & 840 & 39.7 & 16.9 & 4.69 \\
\hline 3 & 0.01 & 252.1 & 236.8 & 840 & 15.3 & 6.1 & 1.82 \\
\hline 4 & 0.01 & 252.5 & 231.5 & 840 & 21.0 & 8.3 & 2.5 \\
\hline 5 & 0.01 & 81.5 & 80.4 & 840 & 1.1 & 1.3 & 0.13 \\
\hline 6 & 0.01 & 81.3 & 65.0 & 840 & 16.3 & 20.0 & 2.38 \\
\hline
\end{tabular}

The main method of preventing fouling of surfaces, at present, is the use of anti-fouling coatings. Most anti-fouling coatings contain certain types of toxins, the gradual entry of which from the coating into the water should lead to the death of the organisms-fouling. As shown by the practice of using anti-fouling coatings, their effectiveness is very limited. 
Currently, there are no universal anti-fouling coatings; on the other hand, many anti-fouling coatings are so toxic that they harm not only organisms-growers, but also all inhabitants of the aquatica, which is unacceptable [5].

The fixation of zebra mussels on the substrate with the help of byssus threads makes the use of traditional anti-fouling coatings containing toxic biocides ineffective, since the concentration of biocide in thin water is sufficient to suppress the vital activity and death of zebra mussels. The zebra mussel, which is attached to the byssus threads, is sufficiently removed from the substrate and uses water for filtration, containing a concentration of biocide that is not dangerous for it. Moreover, even when the zebra mussel dies, its shell remains attached to the substrate and, in turn, serves as a substrate for the formation of other zebra mussels. The formation of zebra mussel due to the growth of some shells onto others, as they are already empty, as well as with live zebra mussel, takes the form of a "fur coat" [5].

Thus, considering the process of fixing byssus threads on the substrate, as the process of forming a glue joint, it can be assumed that the most effective coatings against the formation of zebra mussels will be coatings made of difficult-to-glue materials. Cycloolefins are such materials with low adhesive properties.

To conduct a model experiment to study the anti-fouling properties of coatings on experimental samples, coatings from the indicated compounds were used [6].

To study the anti-fouling and anticorrosive properties of coatings, as well as to determine the adhesion of coatings to metal, the experimental samples were made. When conducting a model experiment at the Department of Water Supply and Sanitation VolgSTU aquarium site the samples were used in the form of plates with a size of $100-100$ $\mathrm{mm}$ and a thickness of no more than $3 \mathrm{~mm}$ from the following materials: steel 3, brass, steel 20.

The application of a cold curing varnish coating on the surface of the samples was carried out according to the following technology: organic compounds of the class of cycloolefins included in the composition SRB - auxins and prostaglandins (growth stimulants and regulators of SRB cell function). For the inhibitor film formation with a thickness of at least 3 microns, the amount of biomass required for $1 \mathrm{~cm} 2$ surface not less than 26-30 $\mathrm{mg}$ [7].

The positive results obtained made it possible to develop a convenient method for the synthesis of the named inhibitor and its mono-alkyl 1,3 - dimethyl, 1,3 - diphenyl butyl, dimethyl carbinol and amino methyl derivatives.

To carry out the model experiment, we prepared the plates of $100-100 \mathrm{~mm}$ in size, 3 $\mathrm{mm}$ thick, made of steel 20 . Steel 20 is best suited for studying the protective properties of the investigated coatings based on cycloolefins and biocorrosion processes. For each sample, the dimensions and weight are fixed, a microscopic survey of the surface was carried out using a microscope MIM-8, the roughness of the control sample surface was measured according to the parameter Ra before and after coating (Figure 1).

For the observation under laboratory conditions for the formation of zebra mussel of various materials in the aquarium (100 1), the samples, on which (small 5-15 shells) colonies of zebra mussels were placed, were installed/

The exposure time was 2 months, after which a visual inspection of the surfaces was carried out.

For testing, from the technological considerations of applying coatings on the equipment surface, protective coatings based on derivatives of cycloolefins were chosen.

The technology of applying the films does not present any particular difficulties and can be used to protect the surfaces of technological equipment, head grids WIF [8]. 


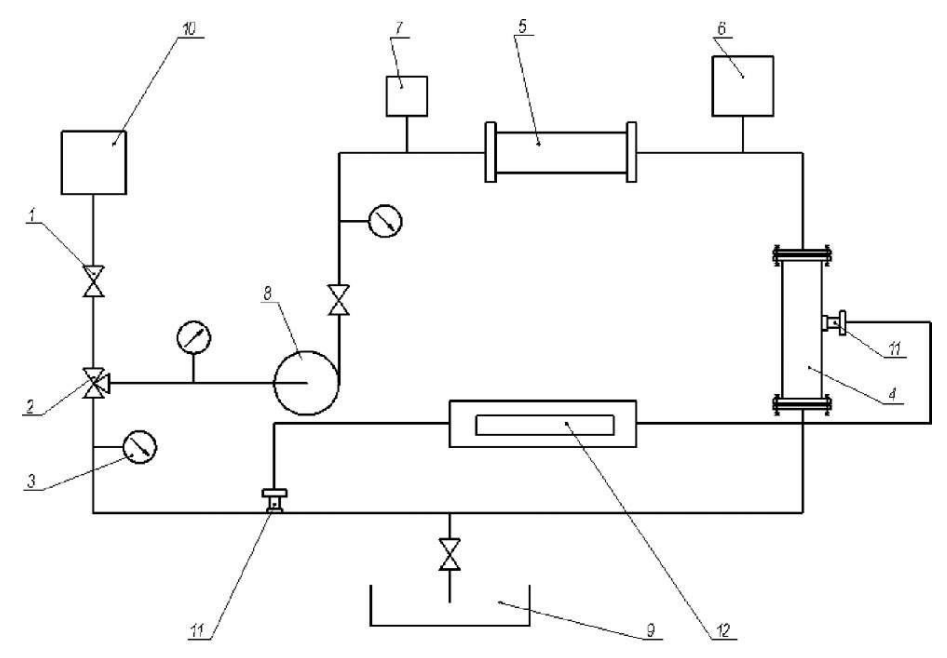

Fig. 1. Scheme of the stand: 1 - gate valve, 2 - valve, 3 - manometer, 4 - anodic oxidation device, 5 control area, 6, 7-thermometers, 8 - pump, 9 - drain, 10 - buffer tank 2 m3, 11 - sensors "Monicor-2", 12 - remote control "Monicor-2".

The assessment was carried out visually and by means of mechanical action with a spatula. An external examination of the lid inner surface revealed no mollusk colonies. The top surface was covered with a brownish-brown coating, under which the coating condition was quite satisfactory. In some places, local, point peeling of the film and metal corrosion were recorded. In the same places, single hardened mollusks were found.

No hardened mollusks were found on the film; sludge accumulated near the partition of the lid, consisting mainly of empty shells and other solid particles. In addition, the film has proven good anti-corrosion protection properties. Under the film, the metal surface remained clean with a characteristic metallic luster without corrosion signs $[9,10]$.

\section{Conclusion}

Summing up the results of the materials studies based on cycloolefins as anti-fouling coatings, the following can be noted:

the coating showed good anti-fouling properties, since no mollusk colonies were found on them;

correct application provides excellent protection against corrosion and good adhesion strength of the metal bond;

the cost of covering one square meter of film is much lower than analogs, simpler and requires much less time.

Thus, a method aimed at reducing the adhesion of surfaces exposed to fouling is promising and coatings can significantly increase efficiency WIF by reducing the negative impact of the formation of these surfaces of equipment and structures by the Zebra mussel mollusk.

The foregoing gives a possibility for the implementation of engineering solutions to improve the environmental safety of water enterprises.

\section{References}

1. A.F Alimov, General Biology Journal 30 (5), 621-631, (1969) 
2. A.F. Alimov, Mollusks. Ways, methods and results of the study 4, 70-72, (1971)

3. A.F. Alimov, Functional ecology of freshwater bivalve mollusks (Nauka, L., 1981)

4. A.F. Alimov, A.N. Golikov Zoology journal 53 (4), 517-530 (1974)

5. S.I. Kuznetsov, The role of microorganisms in the cycle of substances in lakes (Nauka, L., 1970)

6. M.Ya Kirpichenko, V.P. Mikheev, E.P. Shtern, Electric stations 5, (1962)

7. Recommendations for the protection against corrosion and fouling of equipment and metal structures of HPP hydraulic structures (L., 1982)

8. A.G. Timofeev, S.Yu. Kubarev, O.E. Nikolova, S.I. Mileshkin, E.V. Fedulova, Yu.A. Vorontsov, Features of biofouling of the head of water intake structures (Almanac 2019-1 / edited by G.K. Lobacheva) Volgograd (2019)

9. A.F. Alimov, A.A. Lvova, G.E. Makarova, I.N. Soldatova, Growth and age. Methods of studying bivalve mollusks (Nauka, L., 1990)

10. A.F. Alimov, M.I. Orlova, V.E. Panov, Consequences of the introduction of alien species for aquatic ecosystems and the need for measures to prevent it, (Invasive species in the European seas of Russia), Scientific works collection 12-23 (2000) 